\title{
Effect of astragaloside IV and the role of nuclear receptor $R X R \alpha$ in human peritoneal mesothelial cells in high glucose-based peritoneal dialysis fluids
}

\author{
WEIWEI ZHU ${ }^{1 *}$, XIN ZHANG ${ }^{2 *}, \mathrm{KUN} \mathrm{GAO}^{1}$ and XUFANG WANG ${ }^{1}$ \\ Departments of ${ }^{1}$ Nephrology and ${ }^{2}$ Urology, Jiangsu Province Hospital of Chinese Medicine, \\ Affiliated Hospital of Nanjing University of Chinese Medicine, Nanjing, Jiangsu 210029, P.R. China
}

Received December 20, 2018; Accepted July 25, 2019

DOI: $10.3892 / \mathrm{mmr} .2019 .10604$

\begin{abstract}
Peritoneal fibrosis is a serious complication that can occur during peritoneal dialysis (PD), which is primarily caused by damage to peritoneal mesothelial cells (PMCs). The onset of peritoneal fibrosis is delayed or inhibited by promoting PMC survival and inhibiting PMC epithelial-to-mesenchymal transition (EMT). In the present study, the effect of astragaloside IV and the role of the nuclear receptor retinoid $\mathrm{X}$ receptor- $\alpha(\mathrm{RXR} \alpha)$ in PMCs in high glucose-based PD fluids was investigated. Human PMC HMrSV5 cells were transfected with RXR $\alpha$ short hairpin RNA (shRNA), or an empty vector, and then treated with PD fluids and astragaloside IV. Cell viability, apoptosis and EMT were examined using the Cell Counting Kit- 8 assay and flow cytometry, and by determining the levels of caspase-3, E-cadherin and $\alpha$-smooth muscle actin ( $\alpha$-SMA) via western blot analysis. Cell viability and apoptosis were increased, as were the levels of E-cadherin in HMrSV5 cells following treatment with PD fluid. The protein levels of $\alpha$-SMA and caspase- 3 were increased by treatment with PD fluid. Exposure to astragaloside IV inhibited these changes; however, astragaloside IV did not change cell viability, apoptosis, E-cadherin or $\alpha$-SMA levels in HMrSV5 cells under normal conditions. Transfection of HMrSV5 cells with RXR $\alpha$ shRNA resulted in decreased viability and E-cadherin expression, and increased apoptosis and $\alpha$-SMA levels, in HMrSV5 cells treated with PD fluids and co-treated with astragaloside IV or vehicle. These results suggested that astragaloside IV increased cell viability, and inhibited
\end{abstract}

Correspondence to: Dr Xufang Wang, Department of Nephrology, Jiangsu Province Hospital of Chinese Medicine, Affiliated Hospital of Nanjing University of Chinese Medicine, 155 Hanzhong Road, Nanjing, Jiangsu 210029, P.R. China

E-mail: xufang12_wang@163.com

*Contributed equally

Key words: peritoneal dialysis, peritoneal fibrosis, peritoneal mesothelial cells, astragaloside IV, retinoid X receptor- $\alpha$ apoptosis and EMT in PMCs in PD fluids, but did not affect these properties of PMCs under normal condition. Thus, the present study suggested that $\mathrm{RXR} \alpha$ is involved in maintaining viability, inhibiting apoptosis and reducing EMT of PMCs in PD fluid.

\section{Introduction}

Peritoneal dialysis (PD) is an effective alternative treatment for end-stage renal disease (1-4). Peritoneal fibrosis is a serious complication during PD treatment that affects the survival and prognosis of patients undergoing PD. Peritoneal fibrosis is also one of the primary factors leading to withdrawal from treatment (5-7). The components and some bioincompatible properties of peritoneal dialysates, such as low $\mathrm{pH}$,lactate buffer, high sugar, low calcium, plasticizer and glucose degradation products, cause loss of peritoneal mesothelial cells (PMCs), subcutaneous dense zone thickening, interstitial fibrosis, inflammation and neovascularization (8-12). Damage to PMCs is a key initiating factor that leads to peritoneal fibrosis (13-15). After PMCs are damaged, extracellular matrix (ECM) components, including collagen, fibronectin, laminin, proteoglycan and various fibrogenic factors, such as transforming growth factor (TGF)- $\beta 1$, fibroblast growth factor, connective tissue growth factor, platelet derived growth factor, toll-like receptors (TLRs), angiotensin II receptor and receptor tyrosine kinases, are highly expressed or secreted, which interferes with the normal metabolism of the ECM and promoting its overdeposition, ultimately leading to peritoneal fibrosis $(10,16-23)$. Peritoneal fibrosis can be delayed or inhibited by promoting PMC survival and inhibiting PMC epithelial-to-mesenchymal transition (EMT) $(14,16-19,21,22,24)$.

Previous studies have shown that Astragalus membranaceus inhibits peritoneal fibrosis in PD through monocyte chemoattractant protein- 1 and the TGF- $\beta 1$ pathway (25), and ameliorates renal interstitial fibrosis by inhibiting EMT, inflammation, TLR4/NF- $\mathrm{B}$ and cyrillic B (25-27). Astragalus inhibits PMC EMT by downregulating $\beta$-catenin (28). Astragaloside IV is a key compound extracted from Astragalus membranaceus $(27,29,30)$. It has been shown that astragaloside IV inhibits TGF- $\beta 1$-induced PMC EMT through the upregulation of Smad7 in the TGF- $\beta 1 / \mathrm{Smad}$ signaling 
pathway (31). However, the effect of astragaloside IV on viability and apoptosis of PMCs remains unclear.

Retinoid X receptor- $\alpha(\mathrm{RXR} \alpha)$ is a ligand-dependent nuclear receptor expressed in various tissues and cells (32-34). RXR $\alpha$ can form heterodimers with other nuclear receptors, including peroxisome proliferator activated receptor (PPAR), vitamin D receptor (VDR) and thyroid hormone receptors, resulting in the involvement of RXR $\alpha$ in multiple signaling pathways (35-40). Previous studies have shown that vitamin D/VDR can inhibit peritoneal fibrosis and functional deterioration induced by chlorhexidine gluconate by inhibiting PMC EMT (41-43). Telmisartan inhibits peritoneal fibrosis through PPAR- $\gamma$ activation (44). The PPAR- $\beta / \delta$ agonist GW501516 inhibits peritoneal inflammation in peritoneal fibrosis by inhibiting the TGF- $\beta$-activated kinase $1 / \mathrm{NF}-\kappa \mathrm{B}$ pathway (45). The PPAR- $\gamma$ agonists rosiglitazone and pioglitazone protect rat PMCs against PD solution-induced damage $(46,47)$. These previous studies indicated that the RXR signaling pathway is involved in regulating PMC EMT and peritoneal fibrosis. However, the role of RXR $\alpha$ in PMC activity, apoptosis and EMT in peritoneal fibrosis remains unclear.

In the present study, the human PMC HMrSV5 cell line and high glucose-based PD fluids were used as a model (31) to study the effects of astragaloside IV on PMC viability, apoptosis and EMT during PD. The role of RXR $\alpha$ in PMC viability, apoptosis and EMT during PD was also investigated. The findings of the present study may provide important information for the prevention and treatment of PD-induced fibrosis.

\section{Materials and methods}

Construction of $R X R \alpha$ short hairpin RNA (shRNA) plasmid. The synthetic DNA fragment targeting RXR $\alpha$ (GGATCC CGCACTATGGAGTGTACAGCTCAAGAGAGAGCTGTA CACTCCAGTGCTTTTTTCCAAAAGCTT, synthesized by Western Biomedical Technology, Ltd.) and the vector SD1211 (Biovector Science Lab, Inc.) were modified with BamHI and HindIII (Takara Bio, Inc.) at $37^{\circ} \mathrm{C}$ for $30 \mathrm{~min}$. After gel purification, the digested DNA fragment and the vector were ligated using T4 DNA ligase (Takara, Bio, Inc.) and then transfected into DH5 $\alpha$ competent cells (Tiangen Biotech Co., Ltd.) for plasmid amplification. After selection and screening, plasmids were sequenced to confirm successful construction of the shRNA plasmid.

Cell culture and grouping. The human PMC cell line HMrSV5 was obtained from the Type Culture Collection of the Cell Bank of Chinese Academy of Sciences. This cell line was established by Professor Pierre Ronco, Hospital Tenon (Paris, France) (48) and had been used in a number of previous studies (49-52). HMrSV5 cells were cultured in DMEM containing 10\% FBS (Gibco; Thermo Fisher Scientific, Inc.) and 1\% penicillin-streptomycin in an incubator at $37^{\circ} \mathrm{C}$ supplemented with $5 \% \mathrm{CO}_{2}$ and a saturated humidity. To investigate the effects of astragaloside IV (Yuanye Bio-Technology Co., Ltd.) on PMCs in high glucose-based PD fluids, HMrSV5 cells were divided into four groups: i) Normal + vehicle control group, cells were cultured in regular media and treated with DMSO; ii) PD model + vehicle group, cells were cultured in PD fluids and treated with DMSO; iii) normal + astragaloside IV group, cells were cultured in regular media and treated with astragaloside IV; and iv) PD model regular astragaloside IV group, cells were cultured in PD fluids and treated with astragaloside IV. To investigate the role of RXR $\alpha$ in maintaining PMCs in PD fluids, HMrSV5 cells were divided into four groups: i) Blank + vehicle control group, cells were transfected with the SD1211 empty plasmid, cultured in PD fluids and treated with DMSO; ii) RXR $\alpha$ shRNA plasmid + vehicle group, cells were transfected with the RXR $\alpha$ shRNA plasmid, cultured in PD fluids and treated with DMSO; iii) blank + astragaloside IV group, cells were transfected with the SD1211 empty plasmid, cultured in PD fluids and treated with astragaloside IV; and iv) $\mathrm{RXR} \alpha$ shRNA + astragaloside IV group, cells were transfected with the SD1211 RXR $\alpha$ shRNA plasmid, cultured in PD fluids and treated with astragaloside IV. Cells in each group were first transfected with the appropriate plasmid, for $6 \mathrm{~h}$ and then cultured in fresh media for $24 \mathrm{~h}$. These cells were then cultured in PD fluids and astragaloside IV or DMSO was added. The PD fluids used for cell culture were made from original PD fluids with the addition of $10 \%$ FBS. The original PD fluids (Lactate-G4.25\%; cat. no. 6AB9896) were purchased from Guangzhou Baxter Medical Products Co., Ltd. Its components include $4.25 \mathrm{~g}$ glucose, $538 \mathrm{mg}$ sodium chloride, $26 \mathrm{mg}$ calcium chloride, $5.1 \mathrm{mg}$ magnesium chloride and $448 \mathrm{mg}$ sodium lactate $/ 100 \mathrm{ml}$. The final concentration of astragaloside IV in the normal media or PD fluids was $40 \mu \mathrm{g} / \mathrm{ml}$. Astragaloside IV was dissolved in DMSO to make a $40 \mathrm{mg} / \mathrm{ml}$ stock solution. The same volume of DMSO and astragaloside IV stock solution was used to treat cells. All cells were cultured and treated with pertinent chemicals at $37^{\circ} \mathrm{C}$.

Cell Counting Kit-8 (CCK-8) assay. The CCK-8 assay was used to determine the viability of HMrSV5 cells. To investigate the effects of astragaloside IV on the viability of PMCs in PD fluids, HMrSV5 cells in the log phase growth from each group were seeded in triplicate into 96 -well plates at a density $1 \times 10^{5}$ cells $/ \mathrm{cm}^{2}$ and cultured overnight. Cells were treated with astragaloside IV, PD and their respective controls for 24,48 or $72 \mathrm{~h}$. To investigate the role of RXR $\alpha$ in maintaining the viability of PMCs in PD fluids, HMrSV5 cells from each group were seeded in triplicate into 96-well plates at a density $1 \times 10^{5}$ cells $/ \mathrm{cm}^{2}$ and cultured overnight. Following overnight culture, cells were transfected with SD1211 empty vector $\left(0.4 \mu \mathrm{g} / \mathrm{cm}^{2}\right)$ or RXR $\alpha$ shRNA plasmid $\left(0.4 \mu \mathrm{g} / \mathrm{cm}^{2}\right)$ for $6 \mathrm{~h}$ and then cultured in fresh media for $24 \mathrm{~h}$. These cells were then treated with astragaloside IV, PD and DMSO for 24,48 or 72 h. Cell viability was determined using a CCK-8 kit (Sigma-Aldrich; Thermo Fisher Scientific, Inc.) according to the manufacturer's instructions. The absorbance (A) at $450 \mathrm{~nm}$ was measured using a microplate reader (Thermo Fisher Scientific, Inc.). A 96-well plate with medium and CCK reagent was used as a blank control. Cell viability $(\%)=[\mathrm{A}$ (experiment)-A (blank plate)]/A (normal + vehicle control group) $\mathrm{x} 100$; or cell viability $(\%)=[\mathrm{A}$ (experiment)-A (blank plate)]/A (blank + vehicle control group) x100.

Flow cytometry. Flow cytometry was used to examine the level of apoptosis in HMrSV5 cells. To investigate the effects of astragaloside IV on the level of apoptosis of PMCs in PD fluids, HMrSV5 cells were seeded into 6-well plates at a 
density $1 \times 10^{5}$ cells $/ \mathrm{cm}^{2}$, cultured overnight and treated with astragaloside IV, PD and their respective controls for $48 \mathrm{~h}$. To investigate the role of $\mathrm{RXR} \alpha$ in apoptosis of PMCs in PD fluids, HMrSV5 cells were seeded into 6-well plates at a density $1 \times 10^{5}$ cells $/ \mathrm{cm}^{2}$. Following overnight culture, cells were transfected with SD1211 empty vector $\left(0.4 \mu \mathrm{g} / \mathrm{cm}^{2}\right)$ or RXR $\alpha$ shRNA plasmid $\left(0.4 \mu \mathrm{g} / \mathrm{cm}^{2}\right)$ for $6 \mathrm{~h}$ and then cultured in fresh media for $24 \mathrm{~h}$. These cells were then treated with PD and astragaloside IV or DMSO for $48 \mathrm{~h}$. Cells were collected and the rate of apoptosis was determined using a EPICS XL flow cytometer (Beckman Coulter, USA) and Annexin V-PE Apoptosis Detection Kit I (BD Biosciences, 559763) according to the manufacturer's instructions. Briefly, cells were washed twice with cold PBS and then resuspended in 1X Binding Buffer (BD Biosciences, 51-66121E) at a concentration of $1 \times 10^{6}$ cells $/ \mathrm{ml}$. Then, $100 \mu \mathrm{l}$ of the solution $\left(1 \times 10^{5}\right.$ cells $)$ was transferred to a $5 \mathrm{ml}$ culture tube and $5 \mu \mathrm{l}$ of Annexin V-PE (BD Biosciences, 51-65875X) and $5 \mu$ of 7-Amino-actinomycin D (7-AAD; BD Biosciences, 51-68981E) added. The cells were gently vortexed and incubated for $15 \mathrm{~min}$ at room temperature $\left(25^{\circ} \mathrm{C}\right)$ in the dark. $1 \mathrm{X}$ binding buffer $(400 \mu \mathrm{l})$ was added to each tube. Flow cytometry analysis was performed within one hour. The results were analyzed using CytExpert 1.2 software (Beckman Coulter, Inc.).

Western blotting. To investigate the effects of astragaloside IV on caspase-3 levels and EMT of PMCs in PD fluids, HMrSV5 cells were seeded in 6-well plates at a density $1 \times 10^{5}$ cells $/ \mathrm{cm}^{2}$. After overnight culture, cells were treated with astragaloside IV, PD and their respective controls for $48 \mathrm{~h}$. To investigate the role of RXR $\alpha$ on the caspase-3 levels and EMT of PMCs in PD fluids, HMrSV5 cells were seeded in 6-well plates at a density $1 \times 10^{5}$ cells $/ \mathrm{cm}^{2}$. After overnight culture, cells were transfected with SD1211 empty vector $\left(0.4 \mu \mathrm{g} / \mathrm{cm}^{2}\right)$ or RXR $\alpha$ shRNA plasmid $\left(0.4 \mu \mathrm{g} / \mathrm{cm}^{2}\right)$ for $6 \mathrm{~h}$ and then cultured in fresh media for $24 \mathrm{~h}$. These cells were then treated with astragaloside IV, PD and DMSO for $48 \mathrm{~h}$. Cells were collected and lysed using RIPA buffer [50 mM Tris- $\mathrm{HCl}$ (pH 7.4), $150 \mathrm{mM} \mathrm{NaCl}$, $1 \%(\mathrm{v} / \mathrm{v})$ NP40, $0.1 \%$ (w/v) SDS, $0.5 \%$ (w/v) sodium deoxycholate] with protease inhibitor PMSF (100 mM; Beyotime Institute of Biotechnology). Equal amounts of proteins $(50 \mu \mathrm{g})$ were separated by SDS-PAGE on $10 \%$ gels and then transferred onto PVDF membranes. After blocking with 5\% non-fat milk at room temperature for $2 \mathrm{~h}$, membranes were incubated overnight at $4{ }^{\circ} \mathrm{C}$ with the following primary antibodies: E-cadherin (1:500; Abcam, ab1416), $\alpha$-smooth muscle actin ( $\alpha$-SMA; 1:500; Abcam, ab32575), caspase-3 (1:500; Abcam, ab32351), $\beta$-actin (1:500; Abcam, ab179467) or GAPDH (1:1,000; Cell Signaling Technologies, Inc., 2118). This was followed by incubation with horseradish peroxidase-coupled secondary antibodies (1:1,000; Cell Signaling Technologies, Inc.; 7074 and 7076). Bands were visualized using the Enhanced Chemiluminescence Reagent kit (EMD Millipore) and analyzed using the GDS8000 system GelDoc-It310 and software VisionWorks LS v6.5.2 (UVP, LLC).

Knockdown of RXRa expression in HMrSV5 cells and determination of relative $R X R \alpha m R N A$ levels using reverse transcription-quantitative PCR (RT-qPCR). HMrSV5 cells were transfected with SD1211 empty vector $\left(0.4 \mu \mathrm{g} / \mathrm{cm}^{2}\right)$ or
RXR $\alpha$ shRNA plasmid $\left(0.4 \mu \mathrm{g} / \mathrm{cm}^{2}\right)$ using Lipofectamine ${ }^{\circledR}$ 2000 (Invitrogen; Thermo Fisher Scientific, Inc.) and Opti-MEM (Gibco; Thermo Fisher Scientific, Inc.), which was added to cells, incubated for 4-6 $\mathrm{h}$ and then cultured with regular media. After $24 \mathrm{~h}$ of culture, total RNA was extracted from cells using a MiniBEST Universal RNA Extraction kit (Takara Bio, Inc., 9767), according to the manufacturer's instructions, and reverse transcribed using oligo dT primers and a PrimeScript II 1st Strand cDNA Synthesis kit (Takara Bio, Inc., 6210A) according to the manufacturer's instructions. The thermocycling conditions used for the reverse transcription was as follows: $30^{\circ} \mathrm{C} 10 \mathrm{~min}, 42^{\circ} \mathrm{C} 30-60 \mathrm{~min}, 95^{\circ} \mathrm{C} 5 \mathrm{~min}$, and then chilled in ice. Relative mRNA levels were analyzed by RT-qPCR using a PowerUp SYBR Green Master Mix (Applied Biosystems) and an ABI 7500 fast cycler (Applied Biosystems; Thermo Fisher Scientific, Inc.). GAPDH was used for normalization. The relative RXR $\alpha$ mRNA levels were calculated using the $2^{-\Delta \Delta \mathrm{Cq}}$ method after normalization (53). All experiments were repeated three times. The following primers were used: GAPDH forwards, AGATCCCTCCAAAAT CAAGTGG and reverse, GGCAGAGATGATGACCCTTTT; RXR $\alpha$ forward, CGGGAAGGTTCGCTAAGCT, and reverse, TGTTCCAGGCATTTGAGCC. Primers were designed using Primer 5 according to reference sequences in NCBI and synthesized by Invitrogen (Thermo Fisher Scientific, Inc.).

Statistical analysis. Quantitative data are expressed as the mean \pm standard deviation for three experimental repeats. All the data were analyzed using SPSS 17.0 software (SPSS, Inc.). Graphics for quantitative data were processed using Prism 5 (GraphPad). Statistical analysis of the difference among multiple groups was performed by one-way ANOVA followed by the post hoc Student-Newman-Keuls test. Statistical analysis of the difference in RXR $\alpha$ levels in HMrSV5 cells transfected with SD1211 empty vector and those transfected with RXR $\alpha$ shRNA plasmid was performed using Student's t-test. $\mathrm{P}<0.05$ was considered to indicate a statistically significant difference.

\section{Results}

Astragaloside IV enhances the viability of PMCs in PD fluid. To study the effect of astragaloside IV on the viability of PMCs during high-glucose PD, HMrSV5 cells were treated with PD fluid and astragaloside IV, and cell viability was determined using a CCK-8 assay. The viability of HMrSV5 cells was decreased in the PD model + vehicle groups compared with the normal + vehicle controls (Fig. 1). Viability in the PD model group was increased significantly after treatment with astragaloside IV compared with the PD model + vehicle groups (Fig. 1). Under normal conditions, the viability of HMrSV5 cells was not affected by astragaloside IV (Fig. 1). These results suggested that astragaloside IV increased viability of PMCs cultured in PD fluid, but did not affect cell viability under normal conditions.

Astragaloside IV reduces apoptosis of PMCs cultured in PD fluid. To examine the effect of astragaloside IV on the rate of apoptosis in PMCs during high glucose-based PD, PD fluid-treated HMrSV5 cells were used as a PD model. These cells were treated with astragaloside IV or vehicle control, and 


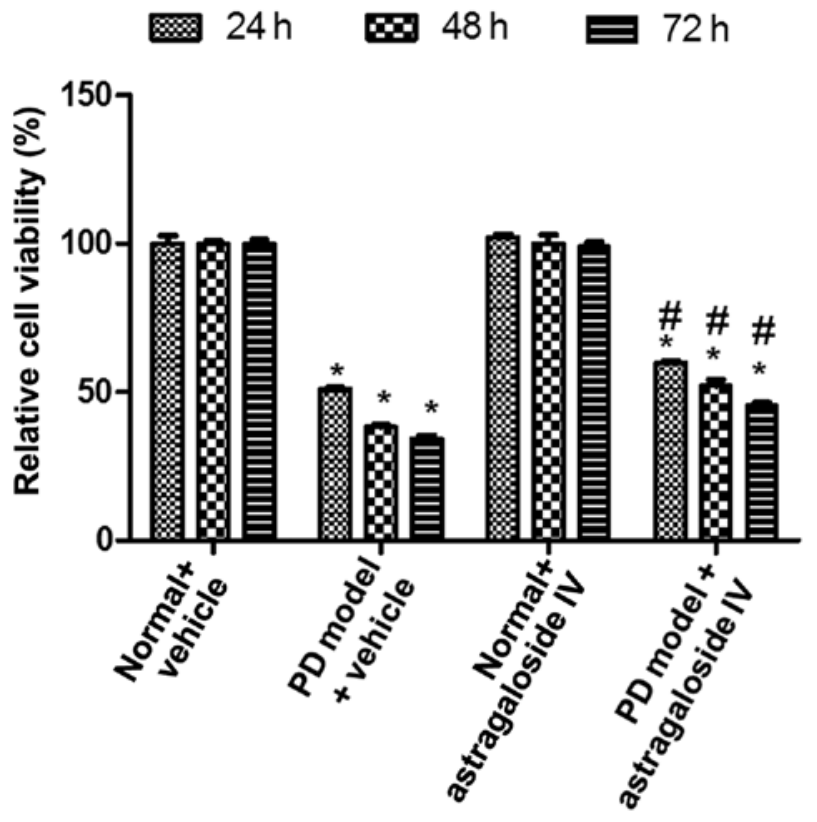

Figure 1. Astragaloside IV enhances the viability of peritoneal mesothelial cells in high-glucose PD fluid. Cultured HMrSV5 cells were treated with high-glucose PD fluid and astragaloside IV for 24,48 or $72 \mathrm{~h}$. Cell viability was determined using the Cell Counting Kit- 8 assay. ${ }^{*} \mathrm{P}<0.05$ vs. normal + vehicle; ${ }^{\#} \mathrm{P}<0.05$ vs. $\mathrm{PD}$ model + vehicle. $\mathrm{PD}$, peritoneal dialysis.

the rate of apoptosis was determined using flow cytometry. Additionally, the protein levels of caspase-3, a hallmark of apoptosis, were determined using western blotting. The number of apoptotic HMrSV5 cells was significantly increased in PD fluids compared with the normal control (Fig. 2A and B). Apoptosis was significantly reduced in PD model cells after treatment with astragaloside IV, while the HMrSV5 cells apoptosis was not affected by astragaloside IV under normal conditions (Fig. 2A and B). Caspase-3 protein levels in HMrSV5 cells were significantly increased in the PD model group compared with the normal control. Caspase-3 levels were significantly decreased in the PD model cells following treatment with astragaloside IV (Fig. 2C). Caspase-3 protein levels were not affected by astragaloside IV under normal conditions (Fig. 2C). These results suggested that astragaloside IV inhibited apoptosis of PMCs in the PD model, but that astragaloside IV did not affect apoptosis under normal conditions.

Astragaloside IV inhibits EMT of PMCs cultured in PD fluid. To investigate the effect of astragaloside IV on EMT of PMCs in PD, HMrSV5 were treated with high-glucose PD fluid and astragaloside IV, and the levels of E-cadherin and $\alpha$-SMA were determined using western blot analysis. The level of E-cadherin was decreased in HMrSV5 cells cultured in PD fluid compared with the normal control (Fig. 3). The level of E-cadherin in the PD model was significantly increased by treatment with astragaloside IV (Fig. 3). The level of $\alpha$-SMA was significantly increased in HMrSV5 cells cultured in PD fluid compared with the normal control (Fig. 3). The level of $\alpha$-SMA was significantly decreased in the PD model after treatment with astragaloside IV (Fig. 3). The levels of both E-cadherin and $\alpha$-SMA were not affected by astragaloside IV under normal conditions (Fig. 3). These results suggested that astragaloside IV inhibited PMC EMT induced by PD fluid, but did not affect PMC EMT under normal conditions.

Knockdown of RXR $\alpha$ expression in HMrSV5 cells. To knockdown the expression of RXR $\alpha$ in HMrSV5 cells, the RXR $\alpha$ shRNA plasmid was constructed using the SD1211 vector and transfected into HMrSV5 cells. The relative expression level of RXR $\alpha$ mRNA was determined using RT-qPCR to examine the effect and efficiency of RXR $\alpha$ shRNA on RXR $\alpha$ expression in HMrSV5 cells. The level of RXR $\alpha$ mRNA was decreased by $\sim 80 \%$ in the HMrSV5 cells after transfection with SD1211 RXR $\alpha$ shRNA compared with the empty vector control (Fig. 4). These data suggested that RXR $\alpha$ expression was significantly and efficiently reduced in HMrSV5 cells by the SD1211 RXR $\alpha$ shRNA plasmid.

$R X R \alpha$ is required to maintain the viability of PMCs in PD fluids. To examine the role of RXR $\alpha$ in maintaining the viability of PMCs during high glucose-based PD, HMrSV5 cells were transfected with SD1211 RXR $\alpha$ shRNA or empty SD1211, these cells were treated with PD fluids and astragaloside IV or vehicle control, and the cell viability was determined using the CCK-8 assay. The results showed that the viability of HMrSV5 cells treated with vehicle or astragaloside IV was decreased after RXR $\alpha$ shRNA transfection compared with the empty vector transfections (Fig. 5). Treatment with astragaloside IV resulted in increases in the viability of HMrSV5 cells after $\mathrm{RXR} \alpha$ shRNA or blank vector transfection compared with the vehicle control treatment (Fig. 5). These results suggested that a decrease in the level of $\mathrm{RXR} \alpha$ results in reduced viability of PMCs in PD fluid. Therefore, $\mathrm{RXR} \alpha$ is required to maintain the viability of PMCs in PD fluid.

$R X R \alpha$ is required to reduce apoptosis and the level of caspase-3 in PMCs cultured in PD fluid. To examine the role of RXR $\alpha$ in the apoptosis of PMCs during high glucose-based PD, HMrSV5 cells were transfected with SD1211 RXR $\alpha$ shRNA or SD1211 empty vector, these cells were treated with PD fluid and astragaloside IV or vehicle control. The rate of apoptosis was determined using flow cytometry and the level of caspase- 3 was determined using western blotting. The results showed that the rate of apoptosis in HMrSV5 cells treated with vehicle or astragaloside IV were increased after RXR $\alpha$ shRNA transfection compared with the blank shRNA transfection (Fig. 6A and B). Treatment with astragaloside IV resulted in decreased apoptosis of HMrSV5 cells transfected with RXR $\alpha$ shRNA or blank vector compared with the vehicle control treatments (Fig. 6A and B). Similar changes in the levels of caspase-3 were observed (Fig. 6C). These results suggested that a decrease in the level of $\mathrm{RXR} \alpha$ resulted in an increase in apoptosis and the level of caspase-3 in PMCs cultured in PD fluid. Therefore, $\mathrm{RXR} \alpha$ may be involved in reducing the apoptosis of PMCs in PD fluids.

RXR $\alpha$ is silencing increased EMT of PMCs cultured in PD fluid. To examine the role of RXR $\alpha$ in EMT of PMCs during high glucose-based PD, HMrSV5 cells were transfected with SD1211 RXR $\alpha$ shRNA or SD1211 empty vector, and cultured in PD fluid with astragaloside IV or vehicle control. The levels of E-cadherin and $\alpha$-SMA were determined using western 
A Normal + vehicle

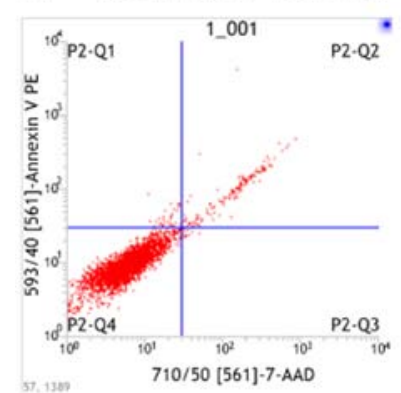

PD model + vehicle

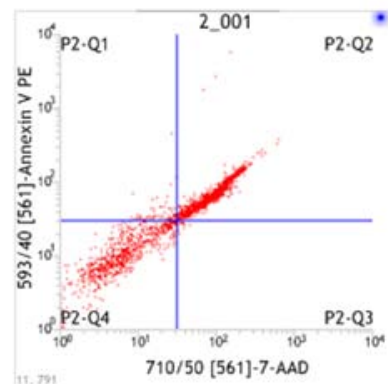

Normal+astragaloside IV PD model+astragaloside IV
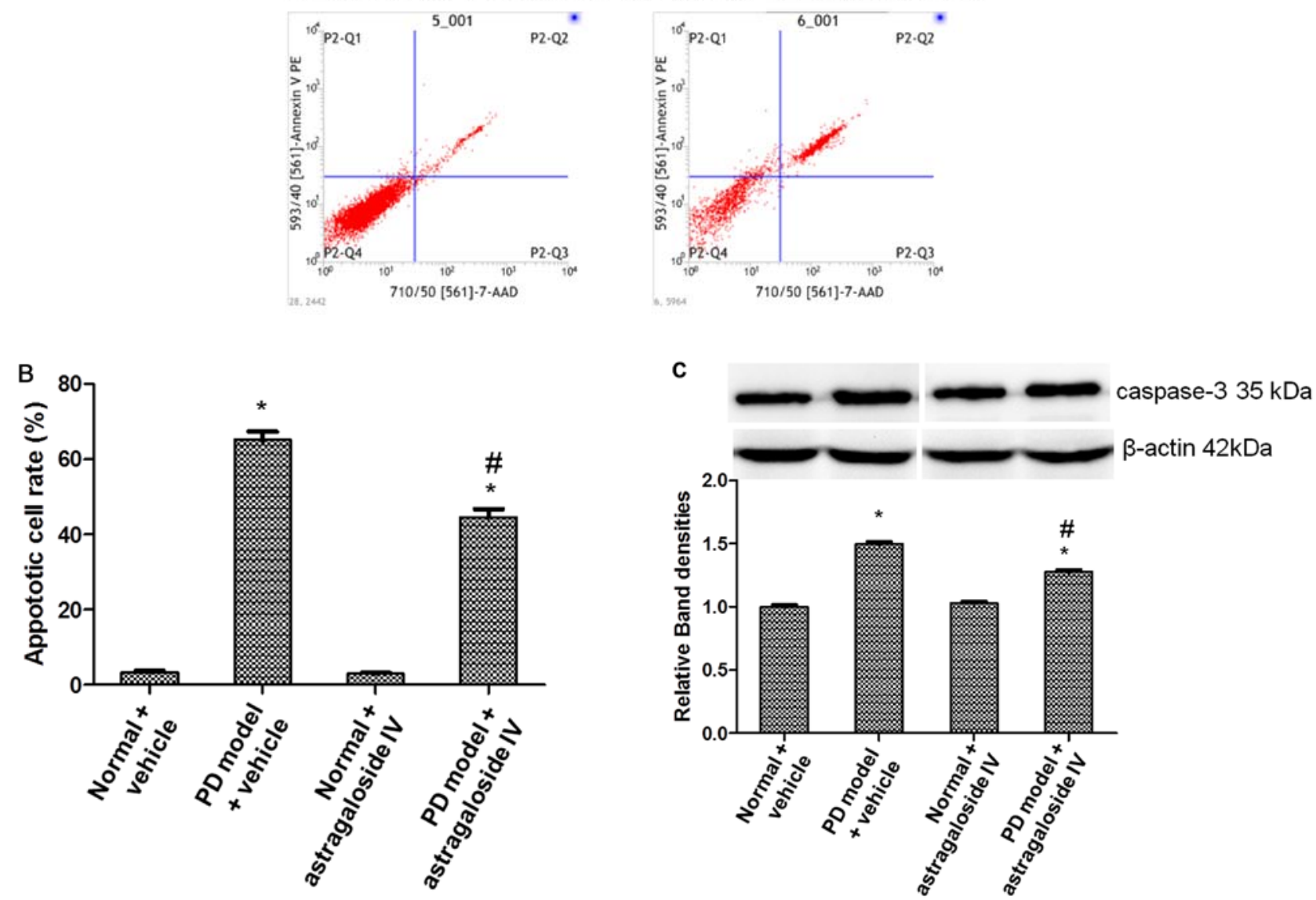

Figure 2. Astragaloside IV inhibits high-glucose PD fluid-induced apoptosis in peritoneal mesothelial cells. HMrSV5 cells were treated with high-glucose PD fluids and astragaloside IV. Apoptotic cells were detected using flow cytometry. (A) Representative results obtained using flow cytometry. (B) Analysis of the results obtained using flow cytometry. (C) Caspase-3 protein levels in HMrSV5 cells treated as indicated were determined using western blotting and quantitative analysis. ${ }^{*} \mathrm{P}<0.05$ vs. normal + vehicle; ${ }^{~} \mathrm{P}<0.05$ vs. PD model + vehicle. PD, peritoneal dialysis; PE, phycoerythrin; 7-AAD, 7-amino-actinomycin $\mathrm{D}$.

blot analysis. The level of E-cadherin in HMrSV5 cells treated with vehicle or astragaloside IV were decreased after RXR $\alpha$ shRNA transfection compared with the blank shRNA transfections (Fig. 7). Treatment with astragaloside IV resulted in an increase in the level of E-cadherin in HMrSV5 cells after RXR $\alpha$ shRNA or blank vector transfections compared the vehicle control treatments (Fig. 7). By contrast, the level of $\alpha$-SMA in HMrSV5 cells treated with vehicle or astragaloside IV were increased after RXR $\alpha$ shRNA transfection compared with the empty shRNA transfections (Fig. 7). Treatment with astragaloside IV resulted in a decrease in the level of $\alpha$-SMA in HMrSV5 cells after RXR $\alpha$ shRNA or empty vector transfections compared with the vehicle control treatments (Fig. 7). These results suggested that a decrease in the level of RXR $\alpha$ resulted in an increase in EMT in PMCs in PD fluid. Therefore, RXR $\alpha$ may be required inhibit EMT in PMCs in PD fluid.

\section{Discussion}

Damage to PMCs is an initiating and important factor in peritoneal fibrosis. A number of preclinical animal and in vitro studies have revealed that the onset of peritoneal fibrosis is delayed or inhibited by promoting PMC survival and inhibiting PMC EMT (8-12,14,16-19,21,22,24). Previous studies have revealed that several drugs can inhibit PMC EMT and inhibit peritoneal 


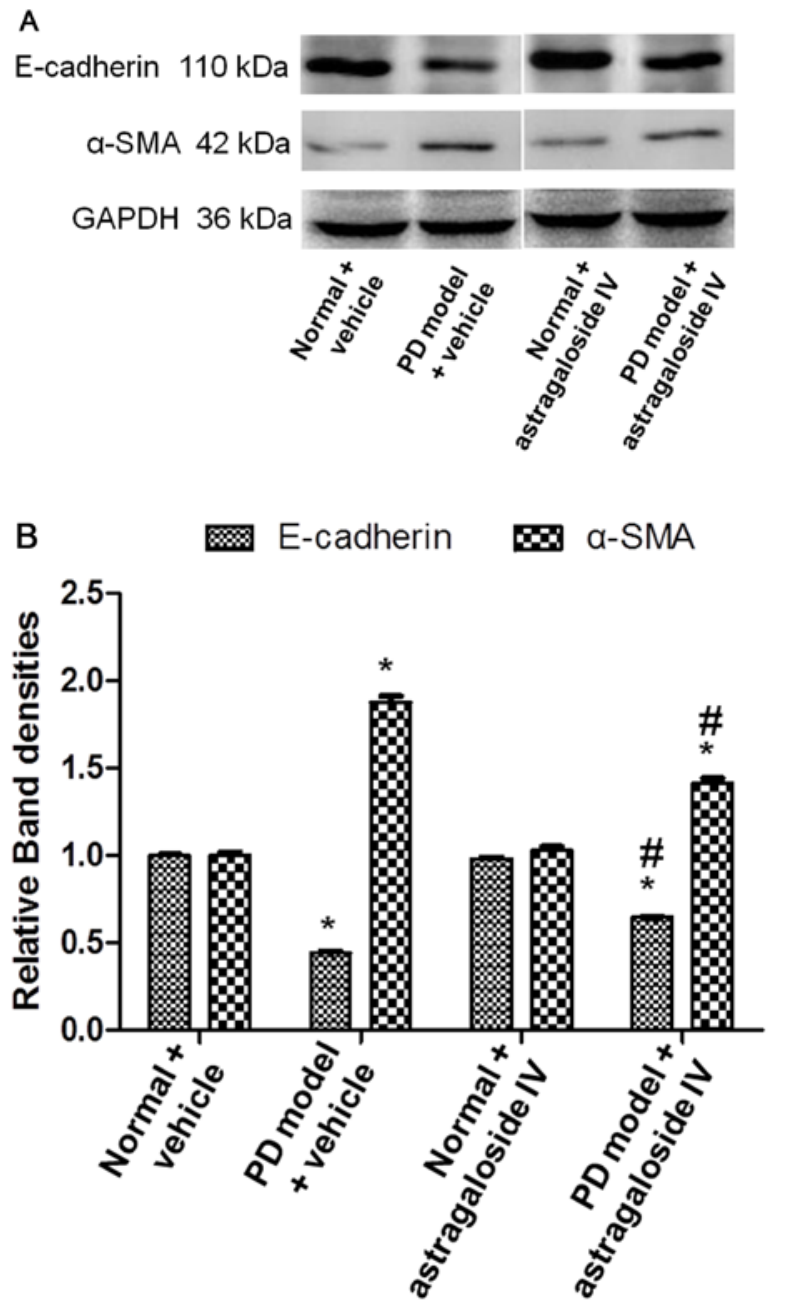

Figure 3. Astragaloside IV inhibits high-glucose PD fluid-induced EMT of peritoneal mesothelial cells. (A) E-cadherin and $\alpha$-SMA protein levels in HMrSV5 cells treated with high-glucose PD fluid and astragaloside IV as indicated. Protein levels were determined using western blotting. (B) Quantitative analysis of western blotting data. ${ }^{*} \mathrm{P}<0.05$ vs. normal + vehicle; ${ }^{\#} \mathrm{P}<0.05$ vs. PD model + vehicle. $\alpha$-SMA, $\alpha$-smooth muscle actin; $\mathrm{PD}$, peritoneal dialysis.

fibrosis. Melatonin can reverse lipopolysaccharide-induced EMT (54). Fluvastatin inhibits high glucose-based PD-induced fibronectin expression in human PMCs via the serum- and glucocorticoid-inducible kinase 1 pathway (55). The histone acetyltransferase inhibitor C646 reverses EMT in human PMCs via the TGF- $\beta / S m a d 3$ signaling pathway (56). The adenosine 5'-monophosphate (AMP)-activated protein kinase activator HL156A protects against peritoneal fibrosis (57). Suramin inhibits the occurrence and deterioration of peritoneal fibrosis (58). Selenium inhibits EMT by regulating reactive oxygen species (ROS) and the ROS/matrix metalloproteinase-9 signaling pathways and the PI3K/AKT pathways in PMCs (59). Hydrogen sulfide can improve peritoneal fibrosis by inhibiting inflammation and TGF- $\beta$ synthesis (60). Metformin ameliorates the transition phenotype of PMCs and peritoneal fibrosis via the modulation of oxidative stress (61). The data in the present study showed that astragaloside IV increases cell viability and inhibits apoptosis and EMT in PMCs cultured in high-glucose PD fluid, without affecting PMCs under normal conditions. This is consistent with a previous report by Zhang et al (31).

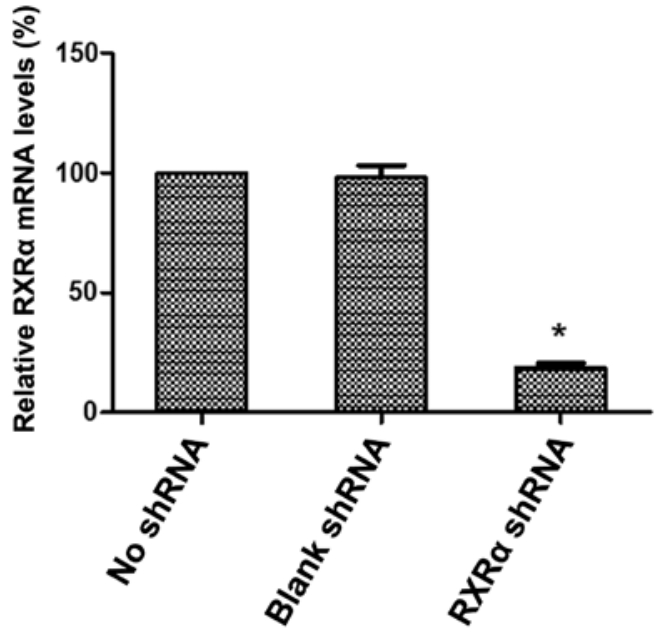

Figure 4. Knockdown of RXR $\alpha$ in HMrSV5 cells using RXR $\alpha$ shRNA. The $\mathrm{RXR} \alpha$ shRNA plasmid was transfected into HMrSV5 cells. The effect and efficiency of the RXR $\alpha$ shRNA transfection were determined using reverse transcription quantitative-PCR. ${ }^{*} \mathrm{P}<0.05$ vs. blank shRNA. RXR $\alpha$, retinoid $\mathrm{X}$ receptor- $\alpha$; shRNA, short hairpin RNA.

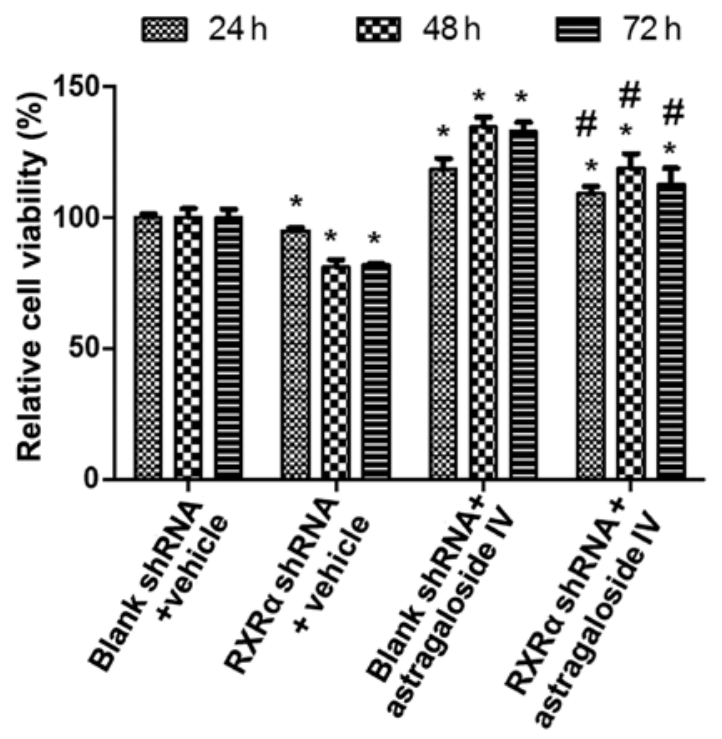

Figure 5. RXR $\alpha$ is required to maintain the viability of peritoneal mesothelial cells in high-glucose PD fluid. HMrSV5 cells were transfected with the RXR $\alpha$ shRNA plasmid or blank vector and treated with astragaloside IV or DMSO in high-glucose PD fluids for 24,48 or $72 \mathrm{~h}$. Cell viability was determined using the Cell Counting Kit- 8 assay. " $\mathrm{P}<0.05$ vs. blank shRNA + vehicle; ${ }^{*} \mathrm{P}<0.05$ vs. blank shRNA + astragaloside IV. $\mathrm{PD}$, peritoneal dialysis; shRNA, short hairpin RNA; RXR $\alpha$, retinoid X receptor- $\alpha$.

Astragaloside IV may be a potential drug that could be used for the inhibition of peritoneal fibrosis.

Previous studies have shown that several signaling pathways are involved in the protective effects of astragaloside IV in different cell types during fibrosis and under high glucose challenge. Astragaloside IV inhibits TGF- $\beta 1 /$ PI3K/AKT-induced forehead box O3a hyper-phosphorylation and downregulation to reverse EMT during the progression of bleomycin-induced pulmonary fibrosis (62). Astragaloside IV has been reported to inhibit renal fibrosis and promote renal function in diabetic KK-Ay mice through inhibition of glucose-induced EMT in glomerular podocytes by activating autophagy and Sirtuin-1 


\section{A Blank shRNA + vehicle}

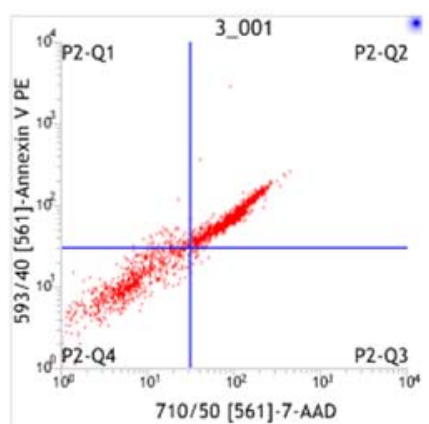

Blank shRNA + astragaloside IV
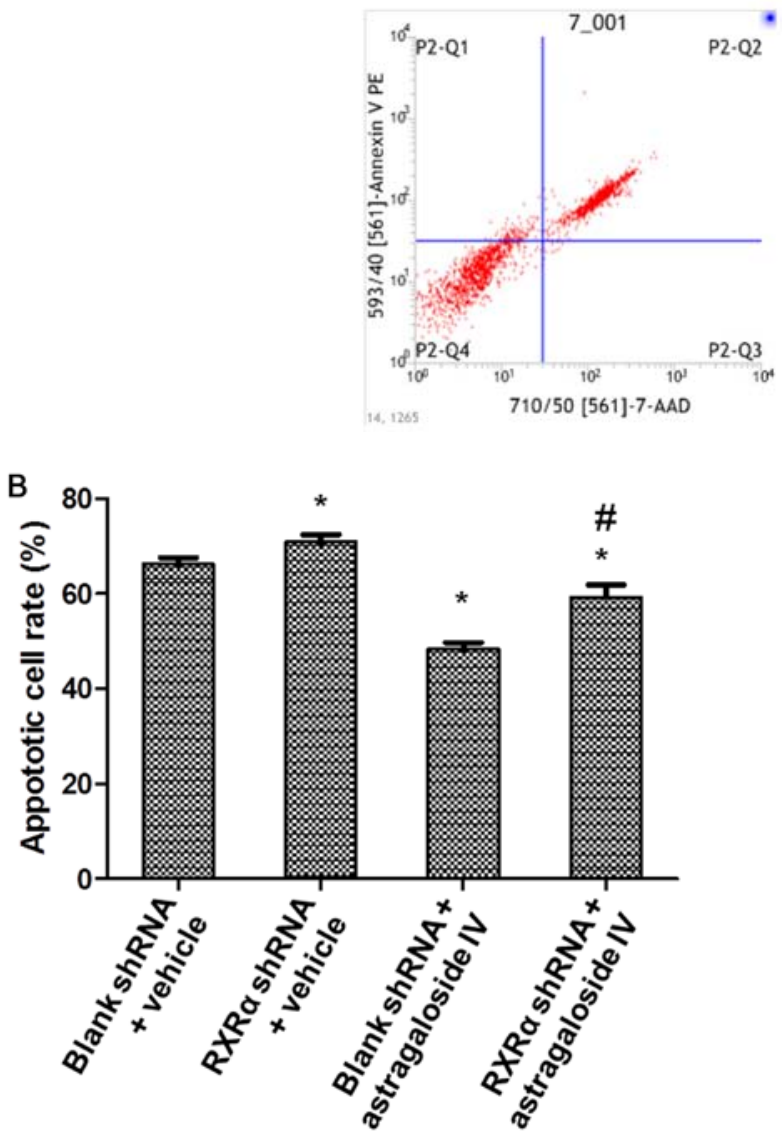

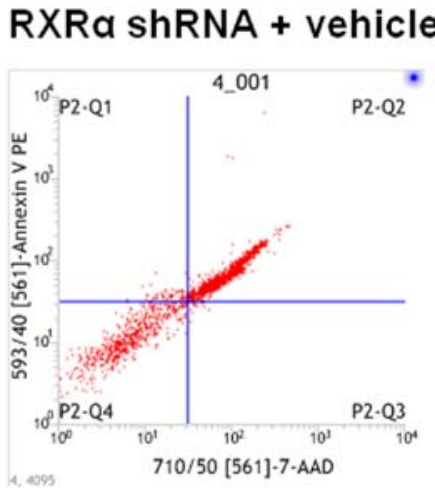

\section{RXRa shRNA + astragaloside IV}

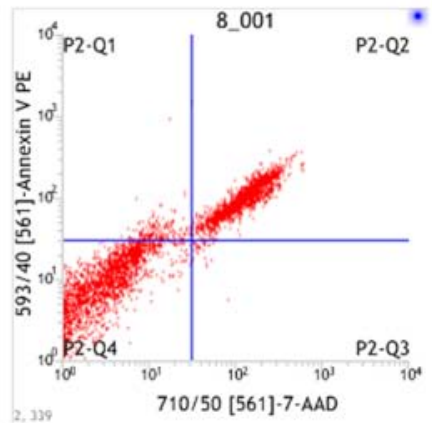

C
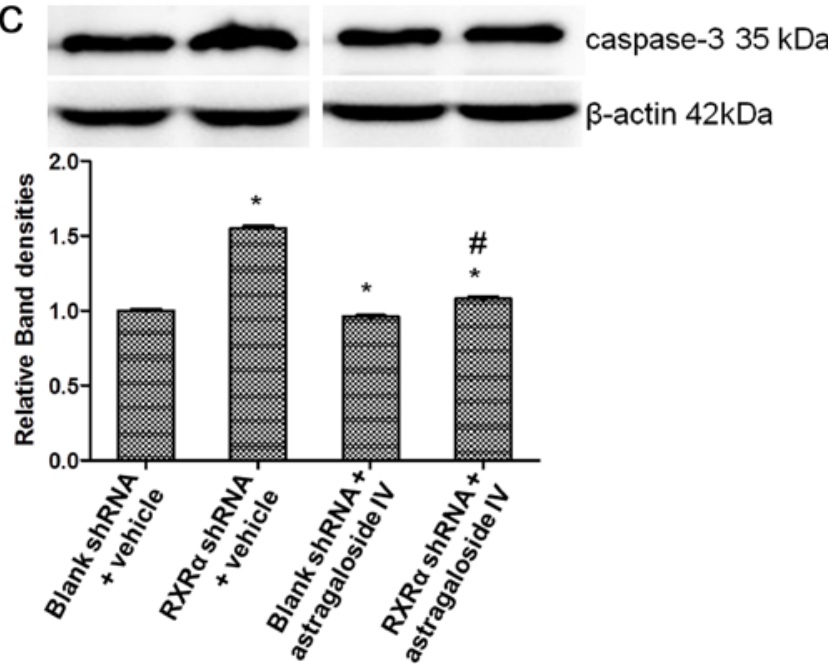

Figure 6. RXR $\alpha$ is required to reduce the rate of apoptosis and the level of caspase 3 in peritoneal mesothelial cells in high-glucose PD fluid. HMrSV5 cells were transfected with RXR $\alpha$ shRNA plasmid or blank vector and treated with astragaloside IV or DMSO in high-glucose PD fluid for 48 h. The rate of apoptosis was examined using flow cytometry. (A) Representative results obtained by flow cytometry. (B) Analysis of the results obtained flow cytometry. (C) Caspase-3 protein levels in HMrSV5 cells treated as indicated were determined using western blotting and densitometry analysis. * $\mathrm{P}<0.05$ vs. blank shRNA + vehicle; ${ }^{\#} \mathrm{P}<0.05$ vs. blank shRNA + astragaloside IV. PD, peritoneal dialysis; shRNA, short hairpin RNA; RXR $\alpha$, retinoid X receptor- $\alpha$; PE, phycoerythrin; 7-AAD, 7-amino-actinomycin D.

expression, which results in decreased acetylation of $\mathrm{NF}-\kappa \mathrm{B}$ subunit p65 (63). Astragaloside IV also downregulates the calcineurin/nuclear factor of activated $\mathrm{T}$ cells/transient receptor potential channel 6 pathway to prevent high glucose-induced podocyte apoptosis (64). Astragaloside IV prevents high glucose-induced apoptosis and inflammatory reactions by inhibiting the JNK pathway in human umbilical vein endothelial cells (65). Astragaloside IV ameliorates high glucose-induced apoptosis and oxidative stress in the human proximal tubular HK-2 cell line by regulating the nuclear factor erythroid 2-related factor 2/antioxidant responsive element (NFE2L2/ARE) signaling pathway (66). Astragaloside IV protects primary cerebral cortical neurons from oxygen and glucose deprivation/reoxygenation by activating the cyclic AMP (cAMP)-dependent protein kinase/cAMP response element-binding protein pathway (67). Astragaloside IV inhibits cell viability, invasion, migration and TGF- $\beta 1$-induced EMT in gastric cancer cells through inhibition of the PI3K/AKT/NF- $\kappa$ B pathway (68). Astragaloside IV inhibits the invasion and migration of hepatocellular carcinoma cells by reducing EMT 

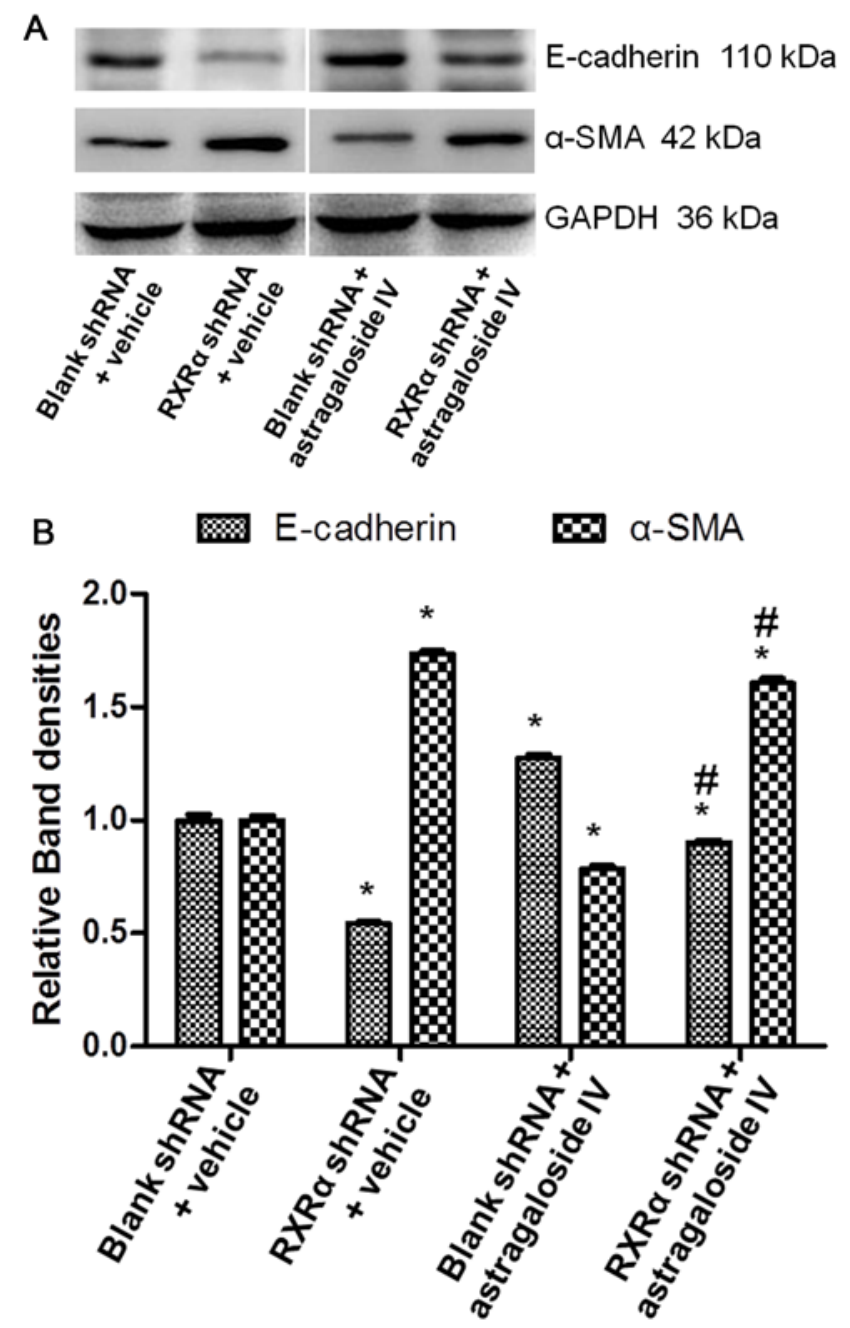

Figure 7. RXR $\alpha$ is required to reduce the rate of EMT in peritoneal mesothelial cells in high-glucose PD fluid. HMrSV5 cells were transfected with RXR $\alpha$ shRNA plasmid or blank vector and treated with astragaloside IV or DMSO in high glucose-based PD fluids for $48 \mathrm{~h}$. (A) Western blotting was used to determine E-cadherin and $\alpha$-SMA levels. (B) Densitometry analysis of western blotting. " $\mathrm{P}<0.05$ vs. blank shRNA + vehicle; ${ }^{\#} \mathrm{P}<0.05$ vs. blank shRNA + astragaloside IV. PD, peritoneal dialysis; $\alpha$-SMA, $\alpha$-smooth muscle actin; shRNA, short hairpin RNA; RXR $\alpha$, retinoid X receptor- $\alpha$.

via effect on the $\mathrm{AKT} / \mathrm{glycogen}$ synthase kinase-3 $\beta / \beta$-catenin pathway (69), and suppressing long noncoding RNA activated by TGF- $\beta$ /interleukin-11/STAT3 signaling (70). Therefore, it is speculated that similar signaling pathways may also be involved in the protective effects of astragaloside IV in PMCs to prevent damage from high glucose-based PD fluids, in addition to the upregulation of Smad7 in the TGF- $\beta 1 / \mathrm{Smad}$ signaling pathway during the inhibition of TGF- $\beta 1$-induced PMC EMT by astragaloside IV (31).

PMC homeostasis is important for resistance against peritoneal fibrosis (13-15). Previous studies have identified several molecular components that are essential for PMC homeostasis. Heat shock protein 70 has been reported to protect PMCs from late glycation end products-induced EMT through the mitogen-activated protein kinase/ERK and TGF- $\beta /$ Smad3 pathways $(71,72)$. NF- $\kappa$ B mediates the inhibition of high glucose induced PMC extracellular matrix synthesis by pioglitazone (46) and the effects of chondroitin sulfate on peritoneal fibrosis (73). Twist promotes cell proliferation and
EMT-induced fibrosis by regulating Y-box binding protein 1 in PMCs (74). Acidic organelles mediate TGF- $\beta 1$-induced cellular fibrosis via (pro)renin receptor and vacuolar ATPase trafficking in human PMCs (75). MicroRNA-15a-5p suppressed PMC EMT (76) and microRNA-21 promoted PMC EMT (77). VDR, PPAR $\gamma$ and PPAR $\beta / \delta$ are also involved in the regulation of PMC activity and homeostasis during peritoneal dialysis (41-47). As RXR $\alpha$ is a dimerization partner for VDR and PPAR, the role of RXR $\alpha$ in PMC homeostasis during PD was investigated. The data from the present study indicated that $\mathrm{RXR} \alpha$ was required to maintain viability, inhibit apoptosis and reduce EMT of PMCs in high glucose-based PD fluid. Therefore, RXR $\alpha$ is an important factor for PMC viability and the ability to resist apoptosis and EMT induction.

It has previously been established that Astragalus membranaceus inhibits peritoneal fibrosis during PD (18-20,22). The data from the present study, and the study by Zhang et al (31), showed that astragaloside IV, a component of Astragalus membranaceus, increased cell viability and inhibited apoptosis and EMT in PMCs in high glucose-based PD fluids without affecting PMCs under normal conditions, suggesting that astragaloside IV is an active, key component of Astragalus membranaceus that contributes to its anti-fibrosis function. It was also shown that $\mathrm{RXR} \alpha$ was required to maintain viability, inhibit apoptosis and reduce EMT in PMCs cultured in high-glucose PD fluids. A limitation of the present study was that the cause-effect relationship between astragaloside IV and $\mathrm{RXR} \alpha$ was not investigated. It has been previously shown that astragaloside IV can bind to glucocorticoid receptor (GR) with a low affinity, modulating the GR-mediated signaling pathway, including dephosphorylation of PI3K, AKT, inhibitor of $\kappa \mathrm{B}$ and $\mathrm{NF}-\kappa \mathrm{B}$ in microglia (78). Astragaloside IV is a natural PPAR $\gamma$ agonist that suppresses the activity of $\beta$-secretase 1 and amyloid $\beta$ (A $\beta)$ levels in $\mathrm{SH}-\mathrm{SY} 5 \mathrm{Y}$ cells, and reduces neuritic plaque formation and $\mathrm{A} \beta$ levels in the brains of APP/PS1 mice, a model of Alzheimer's disease (79). Whether and how the effect of astragaloside IV on PMCs is mediated by $\mathrm{RXR} \alpha$ remains to be determined; this question requires further investigation in future studies.

In conclusion, astragaloside IV increased cell viability, and inhibited apoptosis and EMT of PMCs in high-glucose PD fluid, but did not affect PMCs under normal condition. RXR $\alpha$ silencing reduced viability, inhibited apoptosis and reduced EMT of PMCs in high-glucose PD fluid. Astragaloside IV may be a potential drug that could be used for the inhibition of peritoneal fibrosis. RXR $\alpha$ was found to be an important factor involved in maintaining the viability of PMCs, and in their ability to resist apoptosis and EMT induction. The findings of the present study may provide important information for the prevention and treatment of PD-induced fibrosis.

\section{Acknowledgements}

Not applicable.

\section{Funding}

The present study was supported by the National Natural Science Foundation of China (NSFC; grant nos. 81673912 and 81873259). 


\section{Availability of data and materials}

The datasets used and/or analyzed during the present study are available from the corresponding author on reasonable request.

\section{Authors' contributions}

WZ, XZ and KG performed experiments, and collected and analyzed data. XW conceived the study and wrote the manuscript.

\section{Ethics approval and consent to participate}

Not applicable.

\section{Patient consent for publication}

Not applicable.

\section{Competing interests}

The authors declare that they have no competing interests.

\section{References}

1. Khan S and Rosner MH: Peritoneal dialysis for patients with end-stage renal disease and liver cirrhosis. Perit Dial Int 38: 397-401, 2018.

2. Vareldzis R, Naljayan M and Reisin E: The incidence and pathophysiology of the obesity paradox: Should peritoneal dialysis and kidney transplant be offered to patients with obesity and end-stage renal disease? Curr Hypertens Rep 20: 84, 2018.

3. Javaid MM, Khan BA and Subramanian S: Peritoneal dialysis as initial dialysis modality: A viable option for late-presenting end-stage renal disease. J Nephrol 32: 51-56, 2019.

4. Wang WN, Zhang WL, Sun T, Ma FZ, Su S and Xu ZG: Effect of peritoneal dialysis versus hemodialysis on renal anemia in renal in end-stage disease patients: A meta-analysis. Ren Fail 39 59-66, 2017.

5. Krediet RT, Abrahams AC, de Fijter CWH, Betjes MGH, Boer WH, van Jaarsveld BC, Konings CJAM and Dekker FW: The truth on current peritoneal dialysis: State of the art. Neth J Med 75: 179-189, 2017.

6. Krediet RT and Struijk DG: Peritoneal changes in patients on long-term peritoneal dialysis. Nat Rev Nephrol 9: 419-429, 2013.

7. Bargman JM: Advances in peritoneal dialysis: A review. Semin Dial 25: 545-549, 2012.

8. Davies SJ: Unraveling the mechanisms of progressive peritoneal membrane fibrosis. Kidney Int 89: 1185-1187, 2016.

9. Witowski J, Kawka E, Rudolf A and Jörres A: New developments in peritoneal fibroblast biology: Implications for inflammation and fibrosis in peritoneal dialysis. Biomed Res Int 2015: 134708, 2015

10. Raby AC and Labéta MO: Preventing peritoneal dialysisassociated fibrosis by therapeutic blunting of peritoneal Toll-like receptor activity. Front Physiol 9: 1692, 2018.

11. Zhang Z, Jiang N and Ni Z: Strategies for preventing peritoneal fibrosis in peritoneal dialysis patients: New insights based on peritoneal inflammation and angiogenesis. Front Med 11: 349-358, 2017.

12. Zhou Q, Bajo MA, Del Peso G, Yu X and Selgas R: Preventing peritoneal membrane fibrosis in peritoneal dialysis patients. Kidney Int 90: 515-524, 2016.

13. Lee HB and Ha H: Mechanisms of epithelial-mesenchymal transition of peritoneal mesothelial cells during peritoneal dialysis. J Korean Med Sci 22: 943-945, 2007.

14. De Vriese AS, Tilton RG, Mortier S and Lameire NH: Myofibroblast transdifferentiation of mesothelial cells is mediated by RAGE and contributes to peritoneal fibrosis in uraemia. Nephrol Dial Transplant 21: 2549-2555, 2006.
15. Wu J, Xing C, Zhang L, Mao H, Chen X, Liang M, Wang F, Ren H, Cui H, Jiang A, et al: Autophagy promotes fibrosis and apoptosis in the peritoneum during long-term peritoneal dialysis. J Cell Mol Med 22: 1190-1201, 2018.

16. Dobbie JW: Pathogenesis of peritoneal fibrosing syndromes (sclerosing peritonitis) in peritoneal dialysis. Perit Dial Int 12: 14-27, 1992.

17. Strippoli R, Moreno-Vicente R, Battistelli C, Cicchini C, Noce V, Amicone L, Marchetti A, Del Pozo MA and Tripodi M: Molecular mechanisms underlying peritoneal EMT and fibrosis. Stem Cells Int 2016: 3543678, 2016.

18. Wang L, Liu N, Xiong C, Xu L, Shi Y, Qiu A, Zang X, Mao H and Zhuang S: Inhibition of EGF receptor blocks the development and progression of peritoneal fibrosis. J Am Soc Nephrol 27: 2631-2644, 2016.

19. Morinelli TA, Luttrell LM, Strungs EG and Ullian ME: Angiotensin II receptors and peritoneal dialysis-induced peritoneal fibrosis. Int J Biochem Cell Biol 77: 240-250, 2016.

20. Bartosova M, Schaefer B, Vondrak K, Sallay P, Taylan C, Cerkauskiene R, Dzierzega M, Milosevski-Lomic G, Büscher R, Zaloszyc A, et al: Peritoneal dialysis vintage and glucose exposure but not peritonitis episodes drive peritoneal membrane transformation during the first years of PD. Front Physiol 10: 356, 2019.

21. Choi SY, Ryu HM, Choi JY, Cho JH, Kim CD, Kim YL and Park SH: The role of Toll-like receptor 4 in high-glucose-induced inflammatory and fibrosis markers in human peritoneal mesothelial cells. Int Urol Nephrol 49: 171-181, 2017.

22. Wang $\mathrm{L}$ and Zhuang S: The role of tyrosine kinase receptors in peritoneal fibrosis. Perit Dial Int 35: 497-505, 2015.

23. Tomino Y: Mechanisms and interventions in peritoneal fibrosis. Clin Exp Nephrol 16: 109-114, 2012.

24. Duan S, Yu J, Liu Q, Wang Y, Pan P, Xiao L, Ling G and Liu F: Epithelial-to-mesenchymal transdifferentiation of peritoneal mesothelial cells mediated by oxidative stress in peritoneal fibrosis rats. Zhong Nan Da Xue Xue Bao Yi Xue Ban 36: 34-43, 2011

25. Li Z, Zhang L, He W, Zhu C, Yang J and Sheng M: Astragalus membranaceus inhibits peritoneal fibrosis via monocyte chemoattractant protein (MCP)-1 and the transforming growth factor- $\beta 1$ (TGF- $\beta 1$ ) pathway in rats submitted to peritoneal dialysis. Int J Mol Sci 15: 12959-12971, 2014.

26. Shan G, Zhou XJ, Xia Y and Qian HJ: Astragalus membranaceus ameliorates renal interstitial fibrosis by inhibiting tubular epithelial-mesenchymal transition in vivo and in vitro. Exp Ther Med 11: 1611-1616, 2016.

27. Zhou X, Sun X, Gong X, Yang Y, Chen C, Shan G and Yao Q: Astragaloside IV from Astragalus membranaceus ameliorates renal interstitial fibrosis by inhibiting inflammation via TLR4/NF-KB in vivo and in vitro. Int Immunopharmacol 42: $18-24,2017$.

28. Yu M, Shi J, Sheng M, Gao K, Zhang L, Liu L and Zhu Y: Astragalus inhibits Epithelial-to-Mesenchymal transition of peritoneal mesothelial cells by Down-regulating $\beta$-catenin. Cell Physiol Biochem 51: 2794-2813, 2018.

29. Zhang WD, Chen H, Zhang C, Liu RH, Li HL and Chen HZ: Astragaloside IV from Astragalus membranaceus shows cardioprotection during myocardial ischemia in vivo and in vitro. Planta Med 72: 4-8, 2006.

30. Li W and Fitzloff JF: Determination of astragaloside IV in Radix astragali (Astragalus membranaceus var. monghulicus) using high-performance liquid chromatography with evaporative light-scattering detection. J Chromatogr Sci 39: 459-462, 2001.

31. Zhang L, Li Z, He W, Xu L, Wang J, Shi J and Sheng M: Effects of Astragaloside IV Against the TGF- 31 -induced Epithelial-to-Mesenchymal transition in peritoneal mesothelial cells by promoting Smad 7 expression. Cell Physiol Biochem 37: 43-54, 2015.

32. Fagerberg L, Hallström BM, Oksvold P, Kampf C, Djureinovic D, Odeberg J, Habuka M, Tahmasebpoor S, Danielsson A, Edlund $\mathrm{K}$, et al: Analysis of the human tissue-specific expression by genome-wide integration of transcriptomics and antibody-based proteomics. Mol Cell Proteomics 13: 397-406, 2014.

33. Yue F, Cheng Y, Breschi A, Vierstra J,Wu W, Ryba T, Sandstrom R, Ma Z, Davis C, Pope BD, et al: A comparative encyclopedia of DNA elements in the mouse genome. Nature 515: 355-364, 2014.

34. Bourguet W, Ruff M, Chambon P, Gronemeyer H and Moras D: Crystal structure of the ligand-binding domain of the human nuclear receptor RXR-alpha. Nature 375: 377-382, 1995.

35. Shulman AI and Mangelsdorf DJ: Retinoid x receptor heterodimers in the metabolic syndrome. N Engl J Med 353: 604-615, 2005. 
36. Rastinejad F: Retinoid X receptor and its partners in the nuclear receptor family. Curr Opin Struct Biol 11: 33-38, 2001.

37. Watanabe $M$ and Kakuta $\mathrm{H}$ : Retinoid $\mathrm{X}$ receptor antagonists. Int J Mol Sci 19: pii: E2354, 2018.

38. Reitzel AM, Macrander J, Mane-Padros D, Fang B, Sladek FM and Tarrant AM: Conservation of DNA and ligand binding properties of retinoid $\mathrm{X}$ receptor from the placozoan Trichoplax adhaerens to human. J Steroid Biochem Mol Biol 184: 3-10, 2018

39. Morishita KI and Kakuta H: Retinoid X receptor ligands with anti-type 2 diabetic activity. Curr Top Med Chem 17: 696-707, 2017.

40. Menéndez-Gutiérrez MP and Ricote M: The multi-faceted role of retinoid X receptor in bone remodeling. Cell Mol Life Sci 74 2135-2149, 2017

41. Lee YC, Hung SY, Liou HH, Lin TM, Tsai CH, Lin SH, Tsai YS, Chang MY, Wang HH, Ho LC, et al: Vitamin D can ameliorate chlorhexidine gluconate-induced peritoneal fibrosis and functional deterioration through the inhibition of Epithelial-to-mesenchyma transition of mesothelial cells. Biomed Res Int 2015: 595030 , 2015.

42. Yang L, Wu L, Zhang X,Hu Y,Fan Y and Ma J: 1,25(OH)2D3/VDR attenuates high glucoseinduced epithelialmesenchymal transition in human peritoneal mesothelial cells via the TGF//Smad3 pathway. Mol Med Rep 15: 2273-2279, 2017.

43. Yang L, Wu L, Du S, Hu Y, Fan Y and Ma J: 1,25(OH)2D3 inhibits high glucose-induced apoptosis and ROS production in human peritoneal mesothelial cells via the MAPK/P38 pathway. Mol Med Rep 14: 839-844, 2016.

44. Su X, Yu R, Yang X, Zhou G, Wang Y, Li L and Li D: Telmisartan attenuates peritoneal fibrosis via peroxisome proliferator-activated receptor-gamma activation in rats. Clin Exp Pharmacol Physiol 42: 671-679, 2015

45. Su X, Zhou G, Wang Y, Yang X, Li L, Yu R and Li D: The PPAR $\beta / \delta$ agonist GW501516 attenuates peritonitis in peritoneal fibrosis via inhibition of TAK1-NFKB pathway in rats. Inflammation 37: 729-737, 2014.

46. Zhou G, Su X, Ma J, Wang L and Li D: Pioglitazone inhibits high glucose-induced synthesis of extracellular matrix by NF- $\kappa \mathrm{B}$ and AP-1 pathways in rat peritoneal mesothelial cells. Mol Med Rep 7: 1336-1342, 2013.

47. Zhang YF, Wang Q, Su YY, Wang JL, Hua BJ, Yang S, Feng JX and Li HY: PPAR- $\gamma$ agonist rosiglitazone protects rat peritoneal mesothelial cells against peritoneal dialysis solution-induced damage. Mol Med Rep 15: 1786-1792, 2017.

48. Rougier JP, Moullier P, Piedagnel R and Ronco PM: Hyperosmolality suppresses but TGF beta 1 increases MMP9 in human peritoneal mesothelial cells. Kidney Int 51: 337-347, 1997.

49. Zhao JL, Guo MZ, Zhu JJ, Zhang T and Min DY: Curcumin suppresses epithelial-to-mesenchymal transition of peritoneal mesothelial cells (HMrSV5) through regulation of transforming growth factor-activated kinase 1 (TAK1). Cell Mol Biol Lett 24 32, 2019.

50. Zhang P, Dai $H$ and Peng L: Involvement of STAT3 signaling in high glucose-induced epithelial mesenchymal transition in human peritoneal mesothelial cell line HMrSV5. Kidney Blood Press Res 44: 179-187, 2019.

51. Chu Y, Wang Y, Zheng Z, Lin Y, He R, Liu J and Yang X: Proinflammatory effect of high glucose concentrations on HMrSV5 cells via the autocrine effect of HMGB1. Front Physiol 8: 762, 2017

52. Tani H, Sato Y, Ueda M, Miyazaki Y, Suginami K, Horie A Konishi I and Shinomura T: Role of versican in the pathogenesis of peritoneal endometriosis. J Clin Endocrinol Metab 101: 4349-4356, 2016

53. Livak KJ and Schmittgen TD: Analysis of relative gene expression data using real-time quantitative PCR and the 2(-Delta Delta C(T)) method. Methods 25: 402-408, 2001.

54. Shi S, Zhang Y, Wen W, Zhao Y and Sun L: Molecular mechanisms of melatonin in the reversal of LPS-induced EMT in peritoneal mesothelial cells. Mol Med Rep 14: 4342-4348, 2016.

55. Zhang L, Liu J, Liu Y, Xu Y, Zhao X, Qian J, Sun B and Xing C: Fluvastatin inhibits the expression of fibronectin in human peritoneal mesothelial cells induced by high-glucose peritoneal dialysis solution via SGK1 pathway. Clin Exp Nephrol 19: 336-342, 2015.

56. Yang Y, Liu K, Liang Y, Chen Y, Chen Y and Gong Y: Histone acetyltransferase inhibitor $\mathrm{C} 646$ reverses epithelial to mesenchymal transition of human peritoneal mesothelial cells via blocking TGF- $\beta 1 / \mathrm{Smad} 3$ signaling pathway in vitro. Int J Clin Exp Pathol 8: 2746-2754, 2015.
57. Ju KD, Kim HJ, Tsogbadrakh B, Lee J, Ryu H, Cho EJ, Hwang YH, Kim K, Yang J, Ahn C and Oh KH: HL156A, a novel AMP-activated protein kinase activator, is protective against peritoneal fibrosis in an in vivo and in vitro model of peritoneal fibrosis. Am J Physiol Renal Physiol 310: F342-F350, 2016.

58. Xiong C, Liu N, Fang L, Zhuang S and Yan H: Suramin inhibits the development and progression of peritoneal fibrosis. J Pharmacol Exp Ther 351: 373-382, 2014.

59. Liu J, Zeng L, Zhao Y, Zhu B, Ren W and Wu C: Selenium suppresses lipopolysaccharide-induced fibrosis in peritoneal mesothelial cells through inhibition of epithelial-to-mesenchymal transition. Biol Trace Elem Res 161: 202-209, 2014.

60. Lu Y, Gao L, Li L, Zhu Y, Wang Z, Shen H and Song K: Hydrogen sulfide alleviates peritoneal fibrosis via attenuating inflammation and TGF- $\beta 1$ synthesis. Nephron 131: 210-219, 2015.

61. Shin HS, Ko J, Kim DA, Ryu ES, Ryu HM, Park SH, Kim YL, Oh ES and Kang DH: Metformin ameliorates the phenotype transition of peritoneal mesothelial cells and peritoneal fibrosis via a modulation of oxidative stress. Sci Rep 7: 5690, 2017.

62. Qian W, Cai X, Qian Q, Zhang W and Wang D: Astragaloside IV modulates TGF- $\beta 1$-dependent epithelial-mesenchymal transition in bleomycin-induced pulmonary fibrosis. J Cell Mol Med 22: 4354-4365, 2018

63. Wang X, Gao Y, Tian N, Wang T, Shi Y, Xu J and Wu B Astragaloside IV inhibits glucose-induced epithelial-mesenchymal transition of podocytes through autophagy enhancement via the SIRT-NF-кB p65 axis. Sci Rep 9: 323, 2019.

64. Yao XM, Liu YJ, Wang YM, Wang H, Zhu BB, Liang YP, Yao WG, Yu H, Wang NS, Zhang XM and Peng W: Astragaloside IV prevents high glucose-induced podocyte apoptosis via downregulation of TRPC6. Mol Med Rep 13: 5149-5156, 2016.

65. You L, Fang Z, Shen G, Wang Q, He Y, Ye S, Wang L, Hu M, Lin Y, Liu M and Jiang A: Astragaloside IV prevents high glucoseinduced cell apoptosis and inflammatory reactions through inhibition of the JNK pathway in human umbilical vein endothelial cells. Mol Med Rep 19: 1603-1612, 2019.

66. Wang $\mathrm{J}$ and Guo HM: Astragaloside IV ameliorates high glucose-induced HK-2 cell apoptosis and oxidative stress by regulating the Nrf2/ARE signaling pathway. Exp Ther Med 17: 4409-4416, 2019

67. Xue B, Huang J, Ma B, Yang B, Chang D and Liu J: Astragaloside IV protects primary cerebral cortical neurons from oxygen and glucose deprivation/reoxygenation by activating the PKA/CREB pathway. Neuroscience 404: 326-337, 2019.

68. Zhu J and Wen K: Astragaloside IV inhibits TGF- $\beta 1$-induced epithelial-mesenchymal transition through inhibition of the $\mathrm{PI} 3 \mathrm{~K} / \mathrm{Akt} / \mathrm{NF}-\kappa \mathrm{B}$ pathway in gastric cancer cells. Phytother Res 32: 1289-1296, 2018.

69. Qin CD, Ma DN, Ren ZG, Zhu XD, Wang CH, Wang YC, Ye BG, Cao MQ, Gao DM and Tang ZY: Astragaloside IV inhibits metastasis in hepatoma cells through the suppression of epithelial-mesenchymal transition via the Akt/GSK-3 $\beta / \beta$-catenin pathway. Oncol Rep 37: 1725-1735, 2017.

70. Li Y, Ye Y and Chen H: Astragaloside IV inhibits cell migration and viability of hepatocellular carcinoma cells via suppressing long noncoding RNA ATB. Biomed Pharmacother 99: 134-141, 2018.

71. Yang J, Zhu T, Liu X, Zhang L, Yang Y, Zhang J and Guo M: Heat shock protein 70 protects rat peritoneal mesothelial cells from advanced glycation end-products-induced Epithelial-to-mesenchymal transition through mitogen-activated protein Kinases/extracellular signal-regulated kinases and transforming growth factor- $\beta /$ Smad pathways. Mol Med Rep 11: 4473-4481, 2015.

72. Liu J, Bao J, Hao J, Peng Y and Hong F: HSP70 inhibits high glucose-induced Smad3 activation and attenuates epithelial-to-mesenchymal transition of peritoneal mesothelial cells. Mol Med Rep 10: 1089-1095, 2014.

73. Abe S, Obata Y, Oka S, Koji T, Nishino T and Izumikawa K: Chondroitin sulfate prevents peritoneal fibrosis in mice by suppressing NF- $\kappa B$ activation. Med Mol Morphol 49: 144-153, 2016

74. He L, Che M, Hu J, Li S, Jia Z, Lou W, Li C, Yang J, Sun S, Wang $\mathrm{H}$ and Chen $\mathrm{X}$ : Twist contributes to proliferation and epithelial-to-mesenchymal transition-induced fibrosis by regulating YB-1 in human peritoneal mesothelial cells. Am J Pathol 185: 2181-2193, 2015.

75. Oba-Yabana I, Mori T, Takahashi C, Hirose T, Ohsaki Y, Kinugasa S, Muroya Y, Sato E, Nguyen G, Piedagnel R, et al: Acidic organelles mediate TGF- $\beta 1$-induced cellular fibrosis via (pro)renin receptor and vacuolar ATPase trafficking in human peritoneal mesothelial cells. Sci Rep 8: 2648, 2018. 
76. Shang J, He Q, Chen Y, Yu D, Sun L, Cheng G, Liu D, Xiao J and Zhao $\mathrm{Z}$ : miR-15a-5p suppresses inflammation and fibrosis of peritoneal mesothelial cells induced by peritoneal dialysis via targeting VEGFA. J Cell Physiol 234: 9746-9755, 2019.

77. Gao Q, Xu L, Yang Q and Guan TJ: MicroRNA-21 contributes to high glucose-induced fibrosis in peritoneal mesothelial cells in rat models by activation of the Ras-MAPK signaling pathway via Sprouty-1. J Cell Physiol 234: 5915-5925: 2019.

78. Liu HS, Shi HL, Huang F, Peterson KE, Wu H, Lan YY, Zhang BB, He YX, Woods T, Du M, et al: Astragaloside IV inhibits microglia activation via glucocorticoid receptor mediated signaling pathway. Sci Rep 6: 19137, 2016.
79. Wang X, Wang Y, Hu JP, Yu S, Li BK, Cui Y, Ren L and Zhang LD: Astragaloside IV, a natural PPARgamma agonist, reduces $\mathrm{A} \beta$ production in Alzheimer's disease through inhibition of BACE1. Mol Neurobiol 54: 2939-2949, 2017.

(i) (5) This work is licensed under a Creative Commons Attribution-NonCommercial-NoDerivatives 4.0 International (CC BY-NC-ND 4.0) License. 